\title{
Terror Management and Twitter: The Case of the 2016 Berlin Terrorist Attack
}

\author{
Accepted in proceedings as work in progress for ISCRAM 2018 - International Conference on Information \\ Systems for Crisis response and Management
}

\author{
Diana Fischer \\ University of Bamberg \\ diana.fischer@uni-bamberg.de \\ Kai Fischbach \\ University of Bamberg \\ kai.fischbach@uni-bamberg.de
}

\author{
Carsten Schwemmer \\ University of Bamberg \\ carsten.schwemmer@uni-bamberg.de
}

\begin{abstract}
There is evidence that people increasingly use social networking sites like Twitter in the aftermath of terrorist attacks to make sense of the events at the collective level. This work-in-progress paper focuses on the content of Twitter messages related to the 2016 terrorist attack on the Berlin Christmas market. We chose topic modeling to investigate the Twitter data and the terror management theory perspective to understand why people used Twitter in the aftermath of the attack. In particular, by connecting people and providing a real-time communication channel, Twitter helps its users collectively negotiate their worldviews and re-establish self-esteem. We provide first results and discuss next steps.
\end{abstract}

\section{Keywords}

Terrorist attacks, social networking sites, social media, Twitter, topic modeling, terror management, sensemaking.

\section{INTRODUCTION}

Terrorism is a constant imminent threat and issue of great concern affecting nations and people worldwide (Rogers et al., 2007). Modern terrorism seeks to affect high numbers of victims, aims for global transformation of the world, and is often motivated by religious beliefs. Moreover, terrorists are frequently willing to commit suicide and use weapons of mass destruction. The organization of terrorism is often decentralized and diffuse, with its purveyors united by common goals and/or experiences rather than through direct personal interaction (Crenshaw, 2000). Further, the internet makes it particularly easy for terrorists to receive critical information, such as bombmaking tutorials, which increases the threat of lone actors (Cohen et al., 2013).

Generally, it is recognized that terrorist attacks will continue, thus increasing individuals' fear of becoming a victim (Kruglanski et al., 2013) and creating an increased sense of uncertainty and anxiety (Bux and Coyne, 2009). In the aftermath of terrorist attacks, people have been found to exhibit anxiety-reducing behavior, such as praying, searching for meaning and value, engaging in prosocial and altruistic behavior, exhibiting greater degrees of 
prejudice or stereotyping, and showing less tolerance and greater hostility toward groups different from themselves (Pyszczynski, 2004; Yum and Schenck-Hamlin, 2005).

Terror management theory (TMT) (Greenberg et al., 1986) provides a valuable and widely used explanation of human reactions in the terrorism context (e.g., Das et al., 2009; Dunkel, 2002; Landau et al., 2004). According to TMT (Greenberg et al., 1986), when people are reminded of their vulnerability and mortality due to terrorist attacks, they tend to employ psychological defenses aimed at reducing anxiety by embracing their worldviews (e.g., Western values and lifestyle) to overcome other worldviews (e.g., religiously motivated terrorism) and at enhancing their self-esteem (Dunkel, 2002; Pyszczynski et al., 2003). The validation of cultural worldviews and the maintenance of self-esteem are accomplished largely through interactions with others. Agreement and approval from other people provide support for the "correctness" of one's worldview and help maintain selfesteem, whereas disagreement and disapproval reduce the stability of these psychological factors (Greenberg et al., 1986).

There is also evidence that people increasingly use social networking sites (SNS), such as Facebook and Twitter, in the aftermath of terrorist attacks to make sense of the events and express sympathy at the collective level (Kaufmann, 2015). For instance, shortly after the Charlie Hebdo attacks in Paris in January 2015, the hashtag \#JeSuisCharlie ("I am Charlie") spread across Twitter and Facebook as people expressed solidarity with the victims. It was the most frequently used hashtag on Twitter in the hours after the attacks (Kiwan, 2016). As TMT explains, exchanging opinions and feelings is very important for coping with terrorist attacks and reducing anxiety from the increased need to validate one's feelings and behaviors. Thus, people may use SNS to complement interpersonal communication-for example, to discuss their opinions related to an attack and to receive affirmation from others regarding their own worldviews (Fischer et al., 2016).

Typically, TMT studies use an experimental design and observe human behavior at the individual level (Burke et al., 2010). Despite this rich body of individual-level TMT research, we have less data on and understanding about the reaction to terrorism at the collective level. Therefore, the purpose of this study is to investigate how increased perceptions of mortality salience due to the terrorist attack on the Berlin Christmas market influenced the online behavior of German-speaking Twitter users. To accomplish this goal, we conduct a case study analyzing Twitter content related to the terrorist attack in Berlin on December 19, 2016. The Berlin attack took place at a time of heightened Islamist terrorist activity in Germany and neighboring countries. We provide the theoretical background and first analysis of our Twitter data in this work-in-progress paper.

The paper is organized as follows. In the next section, we provide the theoretical and conceptual background on terrorism, Twitter, sense-making, and TMT. We then present our data-collection process and methodology. Subsequent sections explain our planned data-analysis approach, next steps, and conclusion.

\section{THEORETICAL AND CONCEPTUAL BACKGROUND}

\section{Impacts of terrorism}

A terrorist attack aims to kill non-combatants as a means of influencing the attitudes and actions of individuals, nations, and their leaders (Arquilla, 2007). It is a strategic attack through which a terrorist pursues a goal motivated by religious and/or political commitment (Arquilla, 2007; Kruglanski et al., 2013). This underlying goal is 
typically motivated by an ideology that justifies terrorism - that is, a collective belief system to which the terrorist subscribes (Kruglanski et al., 2013, p 561). Indeed, terrorists justify their actions with the moral conceptions they form of themselves and of the world through an ideology (Atran and Ginges, 2012) that establishes a belief system in which violence against real or imagined enemies is glorified as an effective and worthy way to help one's own group or community (Kruglanski et al., 2013).

Terrorist attacks can be more psychologically threatening and devastating than other types of crises, such as natural disasters, and thus often have a greater impact on society (Danieli et al., 2005). Despite the violence, the ultimate aim of terrorism is psychological (Bux and Coyne, 2009). Anyone in the wrong place at the wrong time can become a victim, which causes people to feel personally and collectively threatened. Such attacks not only injure and kill people, but they also have the potential to destabilize governments, economic development, and civil harmony (Baez et al., 2017). Thus, because these attacks affect many individuals beyond those directly harmed physically, they constitute a social threat (Lerner et al., 2003).

As terrorist attacks are intentional, random, and catastrophic by design, they create high levels of uncertainty and feelings of fear, vulnerability, and distress (Rogers et al., 2007; Bux and Coyne, 2009). They can have both immediate and long-term effects on public health, such as acute or post-traumatic stress disorder (Rogers et al., 2007), and their random nature in terms of who may be targeted also creates an ongoing threat and can increase general perceptions of risk among a populace. For instance, Rubin et al. (2005) stressed that after a bombing attack in London, the majority of Londoners believed they or their family were still in danger. Other researchers have found that the threat of terrorism can influence social behavior, including compelling people to avoid mass events, public places, and public transit (Bux and Coyne, 2009; Crijns et al., 2017).

In summary, terrorism creates feelings of anxiety and threat in broader society and often affects people's behavior. For our context, a particularly relevant behavioral effect caused by the increased fear, uncertainty, and anger after terrorist attacks is an overall change in individuals' media usage, including their social media use (Boyle et al., 2004).

In the next section, we discuss people's SNS usage in the aftermath of crisis events.

\section{Twitter and collective sense-making in the aftermath of crisis events}

Generally, SNS platforms allow users to construct unique profiles, access digital content, and protect that content from search mechanisms. They further enable users to connect with other users of the platform and view their own connections and those between others (Kane et al., 2014). In this study, we focus on Twitter, an SNS that allows users to send and receive short texts with a maximum length of 140 characters at the date of data collection. Twitter also allows users to "follow" other users of interest, which generates notifications of new followers, likes, or repostings of tweets (so-called "retweets" of a user's content). These connections do not require reciprocity; that is, a user who is followed does not have to follow back (Huberman et al., 2009). Content on Twitter is often categorized by annotating tweets with hashtags (e.g., "\#prayforberlin"). The hashtag feature is a crucial mechanism for information diffusion on Twitter and other SNS platforms in the course of crisis events. 
Especially during uncertain and ambiguous crisis events, people engage in sense-making, which we define in accordance with Weick et al. (2005) as the process through which people deal with an uncertain and ambiguous situation by searching for meaning, settling for plausibility, and proceeding. During sense-making, people try to fill the cognitive gaps caused by some uncertain events and thus search for information. As Heverin and Zach (2012) explained, sense-making involves communication between individuals to find missing pieces of information, and during uncertain crisis events, this sense-making process relies heavily on interactions with others.

Making sense of crisis events is, of course, not enabled solely through SNS, but the role of SNS in crisis events has been increasing (Simon et al., 2015; Sutton et al., 2014). Because SNS enable users to interact, collaborate, and upload user-generated content in real time from devices with internet access, such as smartphones, the platforms can be of tremendous use during highly dynamic crisis situations (Mendoza et al., 2010). In addition, the real-time two-way communication and many-to-many information-broadcasting tools provided via SNS allow the public to actively participate during crisis events by browsing others' published information, posting, and leaving public comments (Palen et al., 2009). Thus, people who are not at the crisis scene can also make sense of those events by sharing, commenting, and accessing information posted in SNS (Blum et al., 2014).

Sense-making of crisis events via SNS has also been observed in man-made crises. Heverin and Zach (2012), for instance, investigated people's Twitter usage for collective sense-making during three campus shootings. They found that by following specific hashtags, people could observe not only the specific information posted by others but also their feelings, perspectives, and views. The authors concluded that Twitter served as a communication channel to connect the individual to the collective and helped Twitter users make sense of the events. Also in the aftermath of terrorist attacks, people have a need to discuss and negotiate the meaning behind the attacks with others to develop an understanding of such events (Yum and Schenck-Hamlin, 2005).

The next section introduces TMT, which argues that people who perceive an existential threat take certain social actions and uphold a particular set of values and beliefs.

\section{Terror management theory and Twitter}

The psychological effects of existential threats on people's behavior and attitudes have widely been examined through TMT (Burke et al., 2010). According to TMT, people who have been threatened existentially by reminders of their mortality (i.e., who are under conditions of what is called mortality salience) try to buffer their death anxiety by maintaining their self-esteem and defending their cultural worldviews (Greenberg et al., 1986). TMT claims that when thoughts of death are brought into focus, people immediately try to remove these thoughts by, for example, denying their vulnerability to death (Greenberg et al., 2000). The problem of death, however, resides beneath consciousness, so after a brief distraction from the death-related thought, the so-called distal defensesthat is, the maintenance of worldviews and self-esteem (Pyszczynski et al., 1999) — are typically triggered to buffer death anxiety. The distal defenses are outside the awareness of consciousness and are therefore not particularly obvious to individuals as they employ the defensive behavior (Burke et al., 2010).

One's cultural worldview is a human-constructed belief regarding the nature of reality shared by individuals in a group that helps manage the fear of death by providing a meaningful explanation of life and a comforting conception of the world. The cultural worldview also provides standards for good or bad behavior-namely, a 
way of life, as in a cultural, religious, or political systems - that directs people's behavior to acquire self-esteem. People's self-esteem is their feeling that they are significant and important contributors to their worldview; it helps people attain a literal or symbolic sense of immortality (Greenberg et al., 1986). Self-esteem and cultural worldviews are maintained by social consensus and by individuals' influencing others in accordance with their own worldviews (Pyszczynski et al., 2003).

By outlining why it is so important for people to re-establish their self-esteem and cultural worldviews after death reminders, TMT explains various human behaviors and attitudes after such reminders (Burke et al., 2010). For instance, mortality salience can increase positive feelings about others who share similar religious and political beliefs and negative feelings toward those who differ in these aspects (Cohen et al., 2005), motivate aggression against worldview-threatening others (McGregor et al., 1998), influence people's political preferences (e.g., Landau et al., 2004; Weise et al., 2007), increase people's stereotypical thinking (Schimel et al., 1999), and lead to pro-social behavior (e.g., donating) among those who value these behaviors as a source of self-esteem (Jonas et al., 2016). Taken together, reminders of death make people aware of their mortality, which in turn triggers their need to protect their beliefs through defense strategies for maintaining self-esteem and upholding their cultural beliefs.

According to Pyszczynski et al. (2003), terrorist attacks are "natural" death reminders and can further be seen as attacks against people's cultural worldviews (e.g., basic Western beliefs and values like democracy). In this context, SNS like Twitter help users collectively negotiate their worldviews through their social environment by connecting people and providing a real-time communication channel. In particular, the hashtag feature makes it very easy to follow and find relevant information. The information sent by many different users helps the individual build an overall picture and acquire understanding (Heverin and Zach, 2012). In addition, offering their opinions or personal views helps people verify their feelings and re-establish a secure value system of meaning (Pyszczynski et al., 2003).

In summary, TMT gives us a framework to investigate the utility of communication via Twitter in the aftermath of the Christmas market attack. Hence, to make sense of our data, we use the following eight common distal terrormanagement reactions based on Pyszczynski et al. (2003) that were identified by Yum and Schenk-Hamlin (2005) after the 9/11 attacks as a classification scheme for our further analysis: (1) an increase in the search for meaning and value; (2) nationalistic sentiment, decreased tolerance, and greater hostility toward different values and views; (3) actively countering bigotry; (4) altruistic or prosocial behaviors; (5) gratitude for "heroes" associated with the attacks; (6) increased personal communication; (7) increased information seeking and sharing; and (8) no action. In the next section, we describe our Twitter data on the Christmas market attack in Berlin, show our initial results from our data analysis, and explain our classification scheme in more detail.

\section{METHOD}

\section{Case description}

On December 19, 2016, a truck was hijacked and then intentionally driven into a crowded Christmas market at Breitscheidplatz in Berlin, Germany. Before the truck was finally stopped by its automatic brakes, 12 people had been killed and more than 50 people were injured. One victim was the Polish truck driver who was found murdered 
in the cab. Shortly after the attack, a Pakistani suspect was arrested but released without charge after the police determined he had not been involved in the attack. The police stated that the actual perpetrator was still on the loose, possibly armed and dangerous. On December 21, Anis Amri-a Tunisian who had failed to gain asylum in Germany and was said to have pledged allegiance to the Islamic State terrorist group — was announced as the chief suspect. He was found in Italy on December 23 and shot dead by police after he opened fire (dpa, 2017).

From the time of the initial terrorist attack and over the following days, public authorities used Twitter to inform the public about the investigation.

\section{Data collection and descriptive statistics}

We chose Twitter for our data collection because so many people used the platform to exchange information in the aftermath of the Berlin Christmas market terrorist attack. Although Twitter is not as widely used in Germany as Facebook in terms of general social media activities, it is a crucial platform on which user-generated instant reports of news events circulate. We connected to Twitter's application programming interface (API) to acquire tweets related to the Berlin attack. The API offers several endpoints to extract tweets, most notably the "Search API," which can be utilized to retrieve historical tweets published in the past seven days, and the "Streaming API," which generally allows for retrieving at most a $1 \%$ sample of all tweets for a given query (Morstatter et al., 2013) in real time. To avoid any rate limits, we collected our data with the Search API and collected all tweets including the following (translated) hashtags, which were used in the week of the Berlin attack in Germany: \#berlinassassination, \#breitscheidplatz, \#berlinattack, \#berlinattacks, \#christmasmarketattack, \#prayforberlin, \#prayforgermany, \#Iamaberliner, \#weareberlin, and \#bestrongforberlin. ${ }^{1}$ More specifically, we constructed a query for retrieving all tweets that contained at least one of these hashtags created between December 19 and 25, 2016. We removed retweets and kept only tweets Twitter classified as being in the German language for two reasons. First, our empirical approach requires proper interpretation of a statistical model fitted on large quantities of textual data for which mixing texts of different languages is problematic. Second, because the terrorist attack happened in a German city, we made the assumption that Germans - and thus German speakers - were most likely exposed to the attack by media or locally in Berlin. This approach is not without limitations: for example, Germans could have tweeted in other languages. However, other approaches, such as filtering data by geolocation, are not appropriate alternatives because only a very small share of tweets include information about user location. While our approach might underestimate the total number of tweets referring to the terrorist attack, it enabled us to create a robust data set of relevant tweets. After applying the filtering procedures, our final dataset includes 51,256 tweets posted by 22,439 users.

\footnotetext{
${ }^{1}$ Table A1 in Appendix A shows the original German spellings for these hashtags.
} 


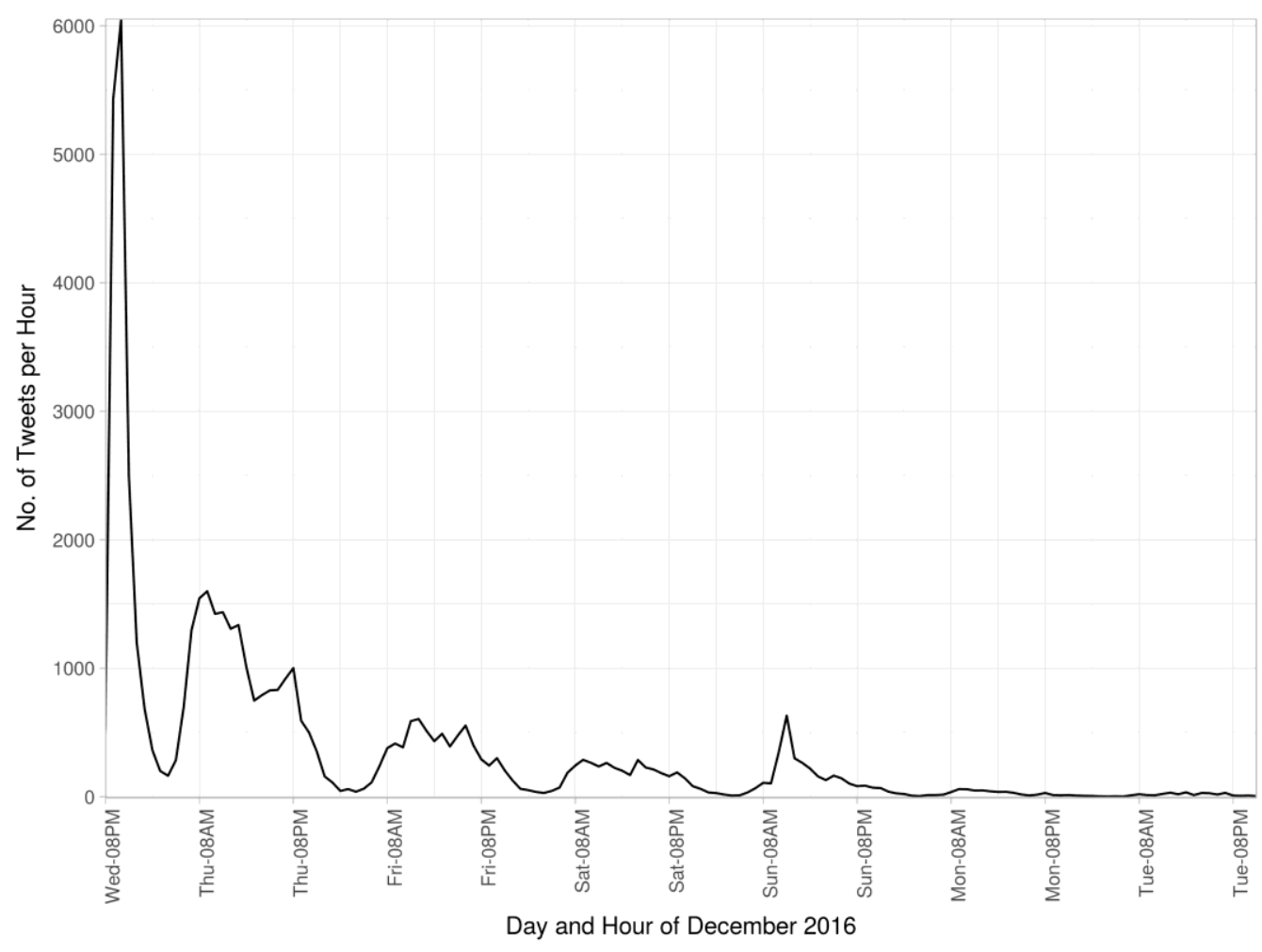

Figure 1. Number of tweets per hour in Germany in the December week of the Berlin attack

Figure 1 shows the number of tweets per hour on the day of the attack and on subsequent days. The plot shows that our sample includes tweets that were posted immediately after the attack took place (around 8:00 p.m.). In addition, most of the Twitter content related to the terrorist attack was posted during the first two days. In contrast, only about $15 \%$ of all tweets were posted between December 21 and December 25 . This is not surprising given that both desire for information and uncertainty are high shortly after a terrorist attack happens-when lives are at stake - and people will urgently seek to clarify the situation to ease their own anxiety and uncertainty (Lachlan et al., 2009).

\section{Topic modeling}

Ideally, human coders would examine and manually annotate each tweet of a dataset to gain detailed insights into SNS usage related to terrorist attacks. As this was not feasible for a dataset comprising more than 50,000 observations, we instead relied on topic modeling as a method for automatic content analysis. Topic models enable the automatic discovery of latent topics from text documents. A topic is a set of words representing interpretable themes within documents (tweets in our dataset). Documents, in turn, are represented as a mixture of these topics. Therefore, after fitting a topic model, a tweet contains proportions of several topics. Generally speaking, a tweet might be ascribed mainly to one certain topic (e.g., with a proportion of 60\%) and to other topics with a smaller proportion (e.g., a proportion of $30 \%$ to a second topic and $10 \%$ among remaining topics). As the tweets at the time of the terrorist attack were limited to 140 characters, their content often strongly refers to one specific topic. As an illustration of this concept using our data, $80 \%$ of topic proportions of the tweet "Our wholehearted sympathy for all victims and their families" posted on December 20 relate to a single topic of one of our topic models. In addition, each topic is modeled as a probability distribution over words, which indicates the most 
important words of a topic. For instance, among the most important words of one of our topics are "happened," "why," and "dead."

To prepare for topic modeling, all tweets were processed into a corpus using common text-analysis methods. Tweets were treated as bags of words, with each term representing a feature and word order being disregarded. In addition, terms without semantic meaning, such as German equivalents for the stop words "the" or "a," were removed from the corpus. Furthermore, to group words with similar semantic meaning, we applied stemming to all words (i.e., reducing inflected words to their word stem), which means that terms like "family" and "families" reduce to the word stem "famili" (Grimmer and Stewart, 2013). In considering the most probable terms, we excluded hashtags that were used to identify tweets related to the Berlin attack such as \#berlinattack because they do not reveal any new information on the topic.

As our data includes not only tweets on the day of the terrorist attack but also of the following days, we expected that content related to the Berlin attack would differ over the course of time. For that reason, we utilized a special variant of topic models called the structural topic model (Roberts et al., 2014; Roberts et al., 2016). In addition to representing documents as distributions over topics, structural topic models allow for the inclusion of documentspecific covariates that influence topic proportions for each document. Drawing on this feature, we incorporated a dummy variable in our model indicating whether a tweet was posted on the day of and the day after the terrorist attack or in the five days following.

Although topic modeling is very useful to categorize large text corpora, it is limited as one must manually determine the number of topics. To fit a model that best represents the data given our attempt to gain insights about Twitter usage during and after terrorist attacks, we fitted four different models with 10, 20, 30, and 40 topics. To determine the best model, we then calculated semantic coherence and exclusivity, which are measures that quantify necessary statistical properties: semantic coherence is higher if more probable words in a topic frequently co-occur together (Mimno et al., 2011), whereas exclusivity is higher if more words are exclusive to their corresponding topics (Lucas et al., 2015). Figure A2 in Appendix A illustrates the average and median values for both measures and all four models. In terms of desirable statistical properties, the figure shows that smaller models with 10 and 20 topics outperform the larger models with 30 and 40 topics.

\section{Manual analysis and next analysis steps}

In addition to statistical diagnostics, validation by humans is the most important way to evaluate topic models (Chang et al., 2009; Wallach et al., 2009). To ease the evaluation procedure, we built a web application based on the R Shiny framework (Winston et al., 2017), which reports the key results and figures of a topic model and thus helps in qualitative data analysis. ${ }^{2}$ In the next step, two of the paper authors will independently investigate the models with 10 and 20 topics by analyzing the most likely words and tweets with the highest proportions for a given topic to determine if the structure makes sense. We will assign corresponding labels in accordance with the highest proportions of words and highly representative documents for each topic. Thereafter, we will compare our

2 At the time of writing, the web application is publicly available at http://www.polsoz.unibamberg.de/stminsights berlin. Should the URL become unavailable, please contact the authors of this paper. The $\mathrm{R}$ package for the application is available at https://github.com/methodds/stminsights. 
results and check the inter-coder reliability (Debortoli et al., 2016). The model that turns out to be the best and most intuitive model in relation to our research task will be chosen as our final model.

Similar to the procedure before, we will make sense of the topics by independently mapping the topics of our final model to typical TMT reactions based on the definitions by Yum and Schenk-Hamlin (2005). Table 1 gives an overview of the eight reactions and corresponding examples.

Table 1. List of TMT reactions

\begin{tabular}{|c|c|c|}
\hline No. & Reaction & Examples \\
\hline 1 & Search for meaning and value & Prayer, going to religious services, candlelight vigil \\
\hline 2 & $\begin{array}{l}\text { Nationalistic sentiment, decreased tolerance, } \\
\text { and greater hostility toward different values and } \\
\text { views }\end{array}$ & $\begin{array}{l}\text { Prejudice, stereotyping, listening to more traditional } \\
\text { patriotic songs, derogating different cultural values }\end{array}$ \\
\hline 3 & Counter-bigotry activism & Calling for tolerance and understanding \\
\hline 4 & Altruistic or prosocial behaviors & Empathy, comforting, donation \\
\hline 5 & $\begin{array}{l}\text { Gratitude for "heroes" associated with the } \\
\text { attacks }\end{array}$ & $\begin{array}{l}\text { Respect for firefighters who helped in the aftermath of } \\
\text { an attack }\end{array}$ \\
\hline 6 & Personal communication & $\begin{array}{l}\text { Calling friends and family, bolstering the value of } \\
\text { relationships }\end{array}$ \\
\hline 7 & Information seeking and sharing & $\begin{array}{l}\text { Watching TV, talking to people for relevant } \\
\text { information }\end{array}$ \\
\hline 8 & No action & - \\
\hline
\end{tabular}

\section{CONCLUSION}

Our purpose is to identify common terror-management reactions on Twitter in the aftermath of the 2016 Berlin Christmas market terrorist attack. According to Pyszczynski et al. (2003), terrorist attacks are "natural" death reminders, and thus, the Twitter users in our data set (i.e., Twitter users who posted something related to the Christmas market terrorist attack) were under conditions of mortality salience. Using TMT, we provide a meaningful explanation of the emergence of psychological needs in the aftermath of terrorist attacks that drive SNS usage - that is, increased needs to defend cultural worldviews and maintain individual self-esteem. Ultimately, the study will contribute to our understanding of people's SNS usage behavior and sense-making via Twitter in the aftermath of terrorist attacks at a collective level. 


\section{REFERENCES}

Arquilla, J. (2007) The end of war as we knew it? Insurgency, counterinsurgency and lessons from the forgotten history of early terror networks. Third World Quarterly, 28 (2), 369-386.

Atran, S. and Ginges, J. (2012) Religious and sacred imperatives in human conflict. Science, 336 (6083), 855857.

Baez, S., Herrera, E., García, A. M., Manes, F., Young, L. and Ibáñez, A. (2017) Outcome-oriented moral evaluation in terrorists. Nature Human Behaviour, 1 (6), 1-18.

Blum, J., Kefalidou, G., Houghton, R., Flintham, M., Arunachalam, U. and Goulden, M. (2014) Majority report: Citizen empowerment through collaborative sensemaking. In: Proceedings of the International Conference on Information Systems for Crisis Response and Management, pp. 767-771.

Boyle, M. P., Schmierbach, M., Armstrong, C. L., McLeod, D. M., Shah, D. V. and Pan, Z. (2004) Information seeking and emotional reactions to the September 11 terrorist attacks. Journalism and Mass Communication Quarterly, 81 (1), 155-167.

Burke, B. L., Martens, A. and Faucher, E. H. (2010) Two decades of terror management theory: A meta-analysis of mortality salience research. Personality and Social Psychology Review: An Official Journal of the Society for Personality and Social Psychology, 14 (2), 155-195.

Bux, S. M. and Coyne, S. M. (2009) The effects of terrorism: The aftermath of the London terror attacks. Journal of Applied Social Psychology, 39 (12), 2936-2966.

Chang, J., Boyd-Graber, J., Gerrish, S., Wang, C. and Blei, D. (2009) Reading tea leaves: How humans interpret topic models. In: Proceedings of the Advances in Neural Information Processing Systems, pp. 1-9.

Cohen, F., Ogilvie, M., Solomon, S., Greenberg, J. and Pyszczynski, T. (2005) American roulette: The effect of reminders of death on support for George W. Bush in the 2004 presidential election. Analyses of Social Issues and Public Policy, 5 (1).

Cohen, K., Johansson, F., Kaati, L. and Mork, J. C. (2013) Detecting linguistic markers for radical violence in social media. Terrorism and Political Violence, 26 (1), 246-256.

Crenshaw, M. (2000) The psychology of terrorism: An agenda for the $21^{\text {st }}$ century. Political Psychology, 21 (3), 405-420.

Crijns, H., Cauberghe, V. and Hudders, L. (2017) Terrorism threat in Belgium: The resilience of Belgian citizens and the protection of governmental reputation by means of communication. Public Relations Review, $\mathbf{4 3}$ (1), 219-234.

Danieli, Y., Brom, D. and Sills, J. (2005) The trauma of terrorism: Contextual considerations. In: The Trauma of Terrorism: Sharing Knowledge and Shared Care, An International Handbook. Danieli, Y., Brom, D., Sills, J. (eds.), pp. 1-18. The Haworth Press, Binghamton, NY.

Das, E., Bushman, B. J., Bezemer, M. D., Kerkhof, P. and Vermeulen, I. E. (2009) How terrorism news reports increase prejudice against outgroups: A terror management account. Journal of Experimental Social Psychology, 45 (3), 453-459.

Debortoli, S., Müller, O., Junglas, I. and Vom Brocke, J. (2016) Text mining for information systems researchers: An annotated topic modeling tutorial. Communications of the Associations for Information Systems, 39 (7), 110-135.

dpa Background [WWW document]. URL https://www.nexis.com/results/enhdocview.do?docLinkInd=true\&ersKey=23_T26851646190\&format=GN BFI\&startDocNo=251\&resultsUrlKey=0_T26851892369\&backKey=20_T26851892370\&csi=144245\&doc No=257, accessed 27 November 2017.

Dunkel, C. S. (2002) Terror management theory and identity: The effect of the 9/11 terrorist attacks on anxiety and identity change. Identity, 2 (4), 287-301.

Fischer, D., Eismann, K. and Fischbach, K. (2016) Usage behavior of social network sites in the aftermath of terrorist attacks. In: Proceedings of the International Conference on Information Systems.

Greenberg, J., Arndt, J., Pyszczynski, T. and Solomon, S. (2000) Proximal and distal defenses in response to reminders of one's mortality: Evidence of a temporal sequence. Personality and Social Psychology Bulletin, 26 (1), 91-99.

Greenberg, J., Pyszczynski, T. and Salomon, S. (1986) The causes and consequences of the need for self-esteem: A terror management theory. In: Public Self and Private Self 1986, pp. 189-212.

Grimmer, J. and Stewart, B. M. (2013) Text as data: The promise and pitfalls of automatic content analysis methods for political texts. Political Analysis, 21 (3), 267-297.

Heverin, T. and Zach, L. (2012) Use of microblogging for collective sense-making during violent crises: A study of three campus shootings. Journal of the American Society for Information Science and Technology, 63 (1), 34-47.

Huberman, B., Romero, D. M. and Wu, F. (2009) Social Networks That Matter: Twitter under the Microscope. First Monday, 14 (1).

Jonas, E., Schimel, J., Greenberg, J. and Pyszczynski, T. (2016) The Scrooge effect: Evidence that mortality 
salience increases prosocial attitudes and behavior. Personality and Social Psychology Bulletin, 28 (10), 1342-1353.

Kane, G. C., Alavi, M., Labianca and Borgatti, S. P. (2014) What's different about social media networks? A framework and research agenda. MIS Quarterly, 38 (1), 274-304.

Kaufmann, M. (2015) Resilience 2.0: Social media use and (self-)care during the 2011 Norway attacks. Media, Culture \& Society, 37 (7), 972-987.

Kiwan, N. (2016) Freedom of thought in the aftermath of the Charlie Hebdo attacks. French Cultural Studies, 27 (3), 233-244.

Kruglanski, A. W., Bélanger, J. J., Gelfand, M., Gunaratna, R., Hettiarachchi, M., Reinares, F., Orehek, E., Sasota, J. and Sharvit, K. (2013) Terrorism-A (self) love story: Redirecting the significance quest can end violence. The American Psychologist, 68 (7), 559-575.

Lachlan, K. A., Spence, P. R. and Seeger, M. (2009) Terrorist attacks and uncertainty reduction: Media use after September 11. Behavioral Sciences of Terrorism and Political Aggression, 1 (2), 101-110.

Landau, M. J., Solomon, S., Greenberg, J., Cohen, F., Pyszczynski, T., Arndt, J., Miller, C. H., Ogilvie, D. M. and Cook, A. (2004) Deliver us from evil: The effects of mortality salience and reminders of 9/11 on support for president George W. Bush. Personality and Social Psychology Bulletin, 30 (9), 1136-1150.

Lerner, J. S., Gonzalez, R. M., Small, D. A. and Fischhoff, B. (2003) Effects of fear and anger on perceived risks of terrorism: A national field experiment. Psychological Science, 14 (2), 144-150.

Lucas, C., Nielsen, R. A., Roberts, M. E., Stewart, B. M., Storer, A. and Tingley, D. (2015) Computer-assisted text analysis for comparative politics. Political Analysis, 23 (2), 254-277.

McGregor, H. A., Liebermann, J. D., Greenberg, J., Solomon, S., Arndt, J., Simon, L. and Pyszczynski, T. (1998) Terror management and aggression: Evidence that mortality salience motivates aggression against worldview-threatening others. Journal of Personality and Social Psychology, 74 (3), 590-605.

Mendoza, M., Poblete, B. and Castillo, C. (2010) Twitter under crisis: Can we trust what we rt? In: $1^{\text {st }}$ Workshop on Social Media Analytics.

Mimno, D., Wallach, H. M., Talley, E., Leenders, M. and McCallum, A. (2011) Optimizing semantic coherence in topic models. In: Proceedings of the Conference on Empirical Methods in Natural Language Processing, pp. 262-272.

Morstatter, F., Pfeffer, J., Liu, H. and Carley, K. M. (2013) Is the sample good enough? Comparing data from Twitter's streaming API with Twitter's firehose. In: Proceedings of the International Conference on Weblogs and Social Media, pp. 400-408.

Palen, L., Vieweg, S., Liu, S. B. and Hughes, A. L. (2009) Crisis in a networked world. Social Science Computer Review, 27 (4), 467-480.

Pyszczynski, T. (2004) What are we so afraid of? A terror management theory perspective on the politics of fear. Social Research, 71 (4), 827-848.

Pyszczynski, T., Greenberg, J. and Solomon, S. (1999) A dual-process model of defense against conscious and unconscious death-related thoughts: An extension of terror management theory. Psychological Review, 106, 835-845.

Pyszczynski, T., Solomon, S. and Greenberg, J. (2003) In the wake of 9/11: The psychology of terror. American Psychological Association, Washington, DC.

Roberts, M. E., Stewart, B. M. and Tingley, D. (2016) Navigating the local modes of big data: The case of topic models. In: Discovery and Prediction, pp. 51-97. Cambridge University Press, Cambridge.

Roberts, M. E., Stewart, B. M., Tingley, D., Lucas, C., Leder-Luis, J. and Rand, D. G. (2014) Structural topic models for open-ended survey responses. American Journal of Political Science, 58 (4), 1064-1082.

Rogers, R. B., Amlôt, R., Rubin, G. J., Wessely, S. and Krieger, K. (2007) Mediating the social and psychological impacts of terrorist attacks: The role of risk perception and risk communication. International Review of Psychiatry, 19 (3), 279-288.

Schimel, J., Simon, L., Greenberg, J., Pyszczynski, T., Solomon, S., Waxmonsky, J. and Arndt, J. (1999) Stereotypes and terror management: Evidence that mortality salience enhances stereotypic thinking and preferences. Journal of Personality and Social Psychology, 77 (5), 5-926.

Simon, T., Goldberg, A. and Adini, B. (2015) Socializing in emergencies-A review of the use of social media in emergency situations. International Journal of Information Management, 35 (5), 609-619.

Sutton, J., Spiro, E. S., Fitzhugh, S., Johnson, B., Gibson, B. and Butts, C. T. (2014) Terse message amplification in the Boston bombing response. In: Proceedings of the International Conference on Information Systems for Crisis Response and Management, pp. 612-621.

Wallach, H. M., Salakhutdinov, I. M. R. and Mimmo, D. (2009) Evaluation methods for topic models. In: Proceedings of the International Conference on Machine Learning.

Weick, K. E., Sutcliffe, K. M. and Obstfeld, D. (2005) Organizing and the process of sensemaking. Organization Science, 16 (4), 409-421.

Weise, D. R., Pyszczynski, T., Cox, C. R., Arndt, J., Greenberg, J., Solomon, S. and Kosloff, S. (2007) 
Interpersonal politics-The role of terror management and attachment processes in shaping political preferences. Psychological Science, 19 (5), 448-455.

Winston, C., Cheng, J., Allaire, J. J., Xie, Y. and McPherson, J. (2017) shiny: Web application framework for $R$. $R$ package version 1.0.5 [WWW document]. URL ttps://CRAN.R-project.org/package=shiny.

Yum, Y. and Schenck-Hamlin, W. (2005) Reactions to 9/11 as a function of terror management and perspective taking. The Journal of Social Psychology, 145 (3), 265-286. 
Table A1. Translation of hashtags

\begin{tabular}{|c|c|}
\hline Original spelling & Translation \\
\hline \#anschlagberlin & \#Berlinattack \\
\hline \#berlinattack & - \\
\hline \#berlinattacks & - \\
\hline \#berlinattentat & \#Berlinassassination \\
\hline \#breitscheidplatz & - \\
\hline \#christmasmarketattack & - \\
\hline \#ichbineinberliner & \#IamaBerliner \\
\hline \#prayforberlin & - \\
\hline \#prayforgermany & - \\
\hline \#wirsindberlin & \#weareBerlin \\
\hline
\end{tabular}

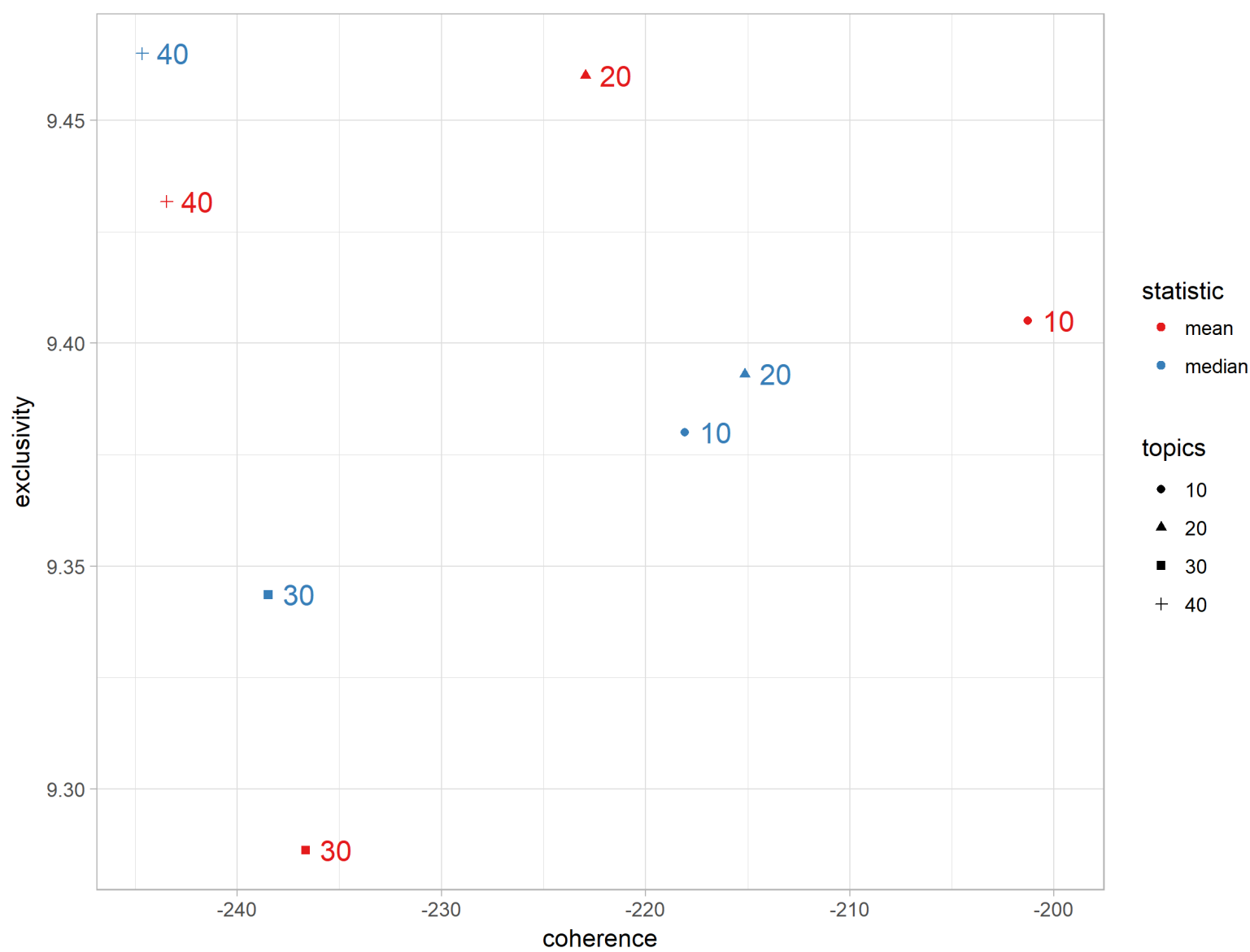

Figure A2. Model diagnostics for structural topic models. Mean and median statistics are computed over all topics of the corresponding model 